The Editor,

\author{
9 St. Andrew Square,
}

EDINBURGH, 2. 24th October 1956.

T.F.A.

Dear SrR,

\title{
Mortality of annuitants
}

Now that so much publicity is being given to the issue of deferred annuities by life offices, I should like to draw attention to some points concerning mortality which may not be generally known outside actuarial circles and possibly only to a minority even there.

I refer to the not inconsiderable chance of major reductions occurring in the mortality at the older ages in future and to the fact that in other parts of the world the mortality actually being experienced by the male population over age 60 is already considerably lighter than the experience among British male life annuitants -a select group of the population.

To take Norway as an example, the mortality actually being experienced now by the male general population at ages 60,70 and 80 is only about 60 to 70 per cent. of the experience of the male population of England and Wales. The present Norwegian population experience at these older ages is actually as light as the projected mortality 20 years hence for British male life annuitants at durations 5 years and over on the basis used for the $a(55)$ tables. These tables were introduced as suitable for immediate annuities commencing in 1955 and for annuities commencing in later years lighter mortality would be appropriate. This difference between the experience of the Norwegian male population and British male life annuitants is due mainly to the higher mortality in Britain from cancer and the cardiovascular diseases, and the much more highly industrialized character of Britain as compared with Norway may well mean that there will always be a difference. However, the fact remains that much research is being devoted here to finding means of reducing the mortality from these causes, and this suggests that spectacular reductions in mortality at the older ages may be achieved by new discoveries perhaps sooner than some are inclined to assume.

The possibility of major reductions in mortality at the older ages, combined with the fact that interest rates at present are historically high, may mean that some of the terms offered for deferred annuities will eventually prove to have been too cheap. 
It is interesting to note that the reductions in the rates of mortality per 1000 of the male population over the past 100 years have been significantly different in Scandinavia and the Netherlands from the reductions in England and Wales, and figures are given below (vide T.F.A. 24, pp. 76-81) to illustrate this fact :-

Reduction in past century in rates of male mortality per 1,000

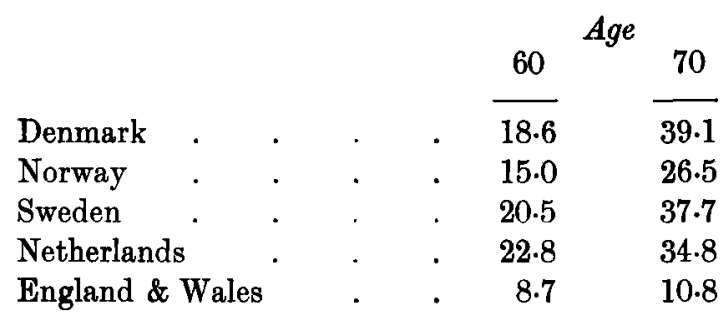

What has happened elsewhere can presumably happen here ! Yours faithfully,

R. LL. GWILT 